\title{
RAPID ASSESSMENT OF PEAK STOREY DRIFT DEMANDS ON REINFORCED CONCRETE FRAME BUILDINGS
}

\author{
Timothy J. Sullivan ${ }^{1}$ \\ (Submitted December 2018; Reviewed May 2019; Accepted July 2019)
}

\begin{abstract}
The peak storey drift demands that an earthquake imposes on a building can be assessed through a detailed engineering seismic assessment or recorded if a building is instrumented. However, for the rapid seismic assessment of a large number of buildings, it is desirable to have a simplified means of estimating storey drift demands. Consequently, this paper proposes a simplified means of quickly estimating storey drift demands on reinforced concrete (RC) frame buildings. Expressions for peak storey drift demand as a function of ground motion intensity are developed by utilising concepts and simplifications available from displacementbased seismic design and assessment methods. The performance of the approach is gauged by comparing predicted storey drift demands with those obtained from rigorous non-linear time-history analyses for a number of case study buildings. The promising results suggest that the approach proposed will be useful for rapidly assessing the likelihood of damage to a range of drift-sensitive elements in modern RC frame buildings.
\end{abstract}

\section{INTRODUCTION}

The 2010-2011 Canterbury earthquakes and the 2016 Kaikoura earthquake have highlighted the vulnerability of ductile reinforced concrete (RC) frame buildings to seismic shaking. In particular, damage to precast flooring systems resulted in the demolition of a number of buildings in the Wellington central business district [1]. In the days following the Kaikoura earthquake, reports of damage to the Statistics House building and other buildings with precast floors prompted the need for rapid assessment of a large building stock. This was addressed by the Wellington City Council initiating targeted damage evaluations based on building typology and location [2]. However, it is recognised [3,4] that the likelihood of observing damage to precast floors can be related to the storey drift demands. The drift demands that a building undergoes in an earthquake can be recorded if a building is instrumented but instrumentation is not common. Alternatively, engineers can perform a detailed seismic assessment of the building but this requires considerable time and detailed information on the building. As such, in order to provide a rapid means of assessing the likely impact of an earthquake on modern RC frame buildings, this paper proposes a simplified means of quickly estimating storey drift demands. It is anticipated that the approach proposed will be useful for assessing the likelihood of damage to a range of drift-sensitive elements and not just precast floors.

The expressions developed herein for the estimation of peak storey drifts utilise concepts and simplifications available from displacement-based seismic design and assessment methods, as will be explained in the next section of this paper. Subsequently, the performance of the approach will be gauged by comparing predicted storey drift demands with those obtained from rigorous non-linear time-history (NLTH) analyses for a number of case study buildings.

\section{A SIMPLIFIED EXPRESSION FOR PEAK DRIFT DEMAND}

\section{Background: Displacement-Based Seismic Design}

Priestley et al. [5] provide guidelines for the Direct displacement-based seismic design (DBD) and assessment of $\mathrm{RC}$ frame structures. Guidance includes an approximate expression, given by Equation 1, which sets an inelastic firstmode displacement profile as a function of the peak storey drift demand. The expression is not theoretical and has instead been calibrated against the results of NLTH analyses of ductile RC frame buildings $[5,6]$.

$\Delta_{i}=\theta_{c} h_{i}\left(\frac{4 H_{n}-h_{i}}{4 H_{n}-h_{1}}\right)$

where $\Delta_{i}$ is the lateral displacement of level $i, \theta_{c}$ is the peak storey drift demand, $H_{n}$ is the total height of the building, $h_{i}$ is the height to level $i$ and $h_{1}$ is the first floor height.

For design to satisfy a specific drift limit, $\theta_{c}$, the displacement profile given by Equation 1 can be used to compute equivalent single-degree-of-freedom characteristics for the building, in line with the substitute structure approach of Gulken and Sozen [7] and Shibata and Sozen [8], as shown in Figure 1(a). Subsequently, the design displacement, $\Delta_{d}$, and damping (which is a function of ductility demand) can be used to identify a required effective period, $T_{e}$, as shown in Figure 1(b). Subsequently, the period and effective mass, $m_{e}$, can be used to compute an effective stiffness, $K_{e}$, which, multiplied by the design displacement, gives the base shear strength (as shown in Figure 1(c)) required to limit the drift demand to $\theta_{c}$. 

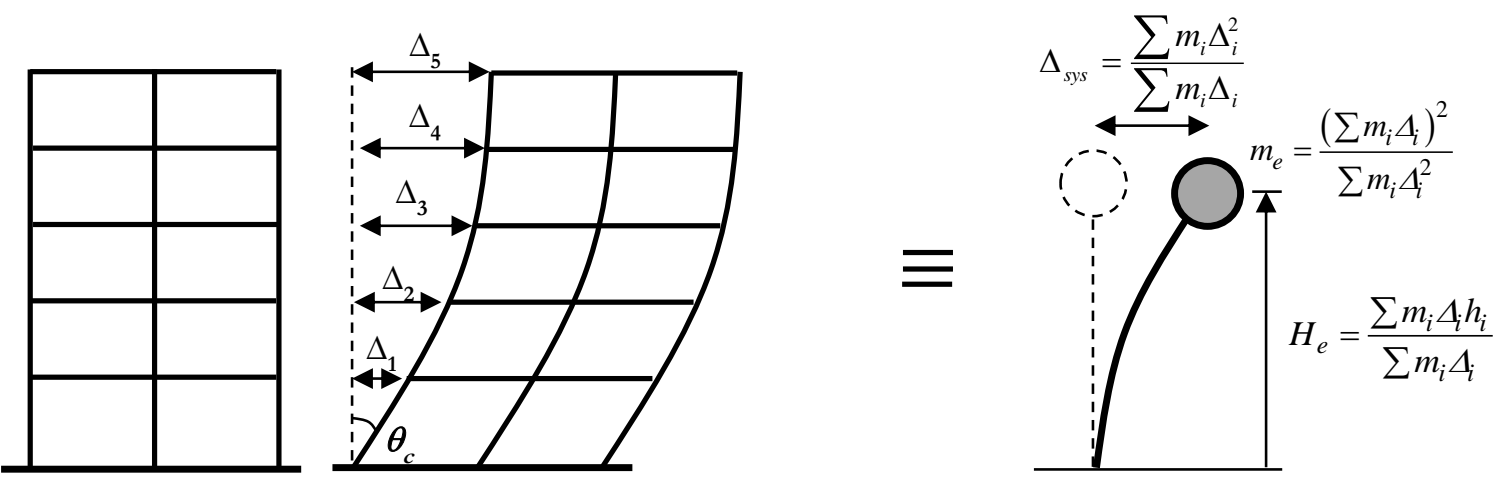

(a) Design displacement profile (left) and equivalent SDOF representation (right)

Spectral

Displacement

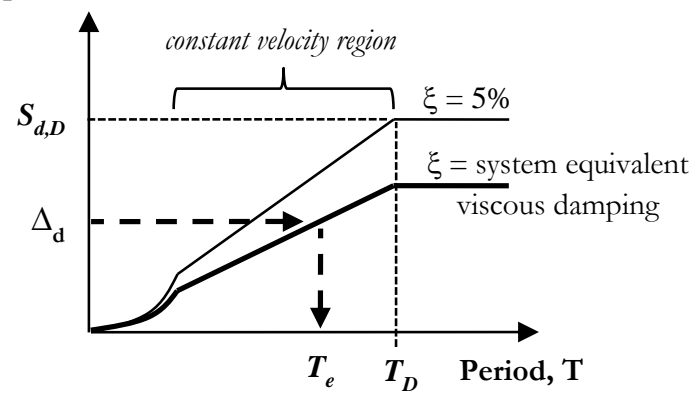

(b) Use of displacement spectrum to find required effective period

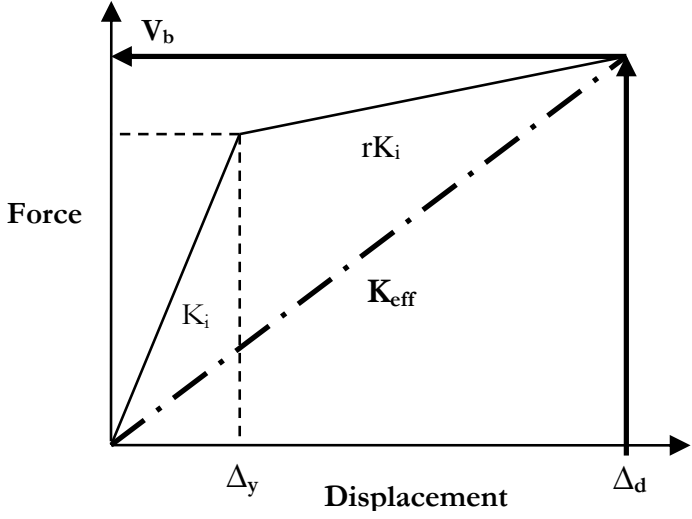

(c) Use of effective stiffness to find required strength

Figure 1: Overview of the displacement-based design approach of Priestley et al. [5].

Sullivan $[9,10]$ has pointed out that the substitute structure characteristics can be identified in a more direct manner to that proposed in [5]. In particular, for RC frame structures it has been shown that an empirical substitute structure factor, $f_{s s}$, given by Equation 2, can be used to simplify the calculation of equivalent SDOF system properties.

$f_{S S}=0.65+\frac{\sqrt{n}-0.65}{n^{2}}$

where $n$ is the number of storeys. This substitute structure factor can be used to quickly compute the effective mass, $m_{e}$, effective height, $H_{e}$, design displacement, $\Delta_{d}$, and frame ductility demand, $\mu$, using Equations 3 to 6 respectively.

$m_{e}=m \sqrt{f_{s S}}$

$H_{e}=H_{n} f_{s s}$

$\Delta_{d}=\theta_{c} H_{n} f_{S S}^{1.5}$

$\mu=\frac{2 \theta_{c} \sqrt{f_{s s}}}{\varepsilon_{y} A_{r}}$

where $m$ is the total mass of the building, $\varepsilon_{y}$ is the yield strain of longitudinal reinforcement, $A_{r}$ is the beam aspect ratio that is obtained by dividing the length of the beams (between column centres) by the beam section depth, and all the other symbols have been defined earlier. The Appendix provides information clarifying the basis of Equation 6.

Reviewing Equations 3 to 6, it can be seen that for RC frames, $f_{s s}$ is equivalent to both the square of the effective mass ratio $\left(m_{e} / m\right)$ and the effective height ratio $\left(H_{e} / H_{n}\right)$. For wall buildings [9] and other structural typologies, separate expressions are required to adequately quantify these substitute structure properties. However, the single factor for RC frames is clearly quite convenient.
In the constant velocity portion of a response spectrum, the required effective period can be computed simply as the ratio of the design displacement to the damped spectral displacement demand at a reference value of period, as shown:

$T_{e}=\frac{\Delta_{d}}{\eta S_{d, D}} T_{D}=\frac{2 \pi \Delta_{d}}{\eta P S V}$

where $T_{D}$ and $S_{d, D}$ are the period and spectral displacement demand, respectively, for a point on the spectrum within the constant velocity portion (see Figure $1 b$ ), $P S V$ is the peak spectral velocity demand $\left(P S V=2 \pi S_{d, D} / T_{D}\right)$ and $\eta$ is a scaling factor to account for the effects of hysteretic energy dissipation on displacement demands, given for RC frames by:

$\eta=\sqrt{\frac{1}{1+8.07\left(\frac{\mu-1}{\mu \pi}\right)}}$

where $\mu$ is the displacement ductility demand (from Equation $6)$.

As explained in [10], Equation 8 has been obtained by combining the spectrum scaling expression for damping with the ductility-dependent equivalent viscous damping equation for RC frames recommended in [5].

The design base shear strength in the Direct DBD procedure is obtained as the product of the effective stiffness and the design displacement, which can be expressed in equation form $[9,10]$ as:

$V_{b}=\frac{4 \pi^{2} m_{e}}{T_{e}^{2}} \Delta_{d}=\frac{P S V^{2} m_{e} \eta^{2}}{\Delta_{d}}$

where the right side has been obtained by introducing the expression for effective period given by Equation 7 . 
Reflecting on the form of the simplified expression for design strength given by Equation 9, note that if one multiplies both sides of the equation by $\Delta_{d}$, the expression represents an energy balance between demand and capacity, with mass times velocity squared representing demand and the base shear (internal resisting force) times displacement representing capacity, with the effects of energy dissipation accounted for with the factor $\eta$. This point is discussed further in [9].

While Equation 9 is only directly applicable in the constant velocity portion of the response spectrum, Sullivan [10] also points out that for short period systems the design base shear strength need not exceed that obtained from the spectral acceleration plateau, such that Equation 9 becomes:

$V_{b}=\frac{P S V^{2} m_{e} \eta^{2}}{\Delta_{d}} \leq \eta \cdot m_{e} P S A$

where PSA is the peak spectral acceleration demand, corresponding to the spectral acceleration demand on the plateau of the elastic acceleration response spectrum being used for design.

\section{Means of Accounting for Complex Phenomena}

Detailed publications on the Direct DBD approach include recommendations to account for a range of complex phenomena, including higher mode effects, P-delta effects and torsion. A summary of the key provisions are provided below as these will be referred to subsequently as part of the simplified assessment procedure being proposed herein.

Considering the frame displacement profile shown in Figure 1(a), the design storey drift limit, $\theta_{c}$, is seen to occur at the ground storey level. However, this is just a design simplification and as explained in [11], due to higher mode effects and the actual lateral stiffness, one could expect the peak storey drift to occur at the $2^{\text {nd }}$ or $3^{\text {rd }}$ storey or over upper storeys. To account for higher mode effects tending to increase peak storey drift demands over and above those of the $1^{\text {st }}$ mode, a higher mode factor, $\omega_{\theta}$, is recommended ([5], [12]), given by Equation 11:

$$
\begin{array}{ll}
\omega_{\theta}=1.0 & \text { for } \quad \mathrm{n} \leq 6 \\
\omega_{\theta}=1.0-0.015 \times(n-6) & \text { for } 6<\mathrm{n}<16 \\
\omega_{\theta}=0.85 & \text { for } \mathrm{n} \geq 16
\end{array}
$$

where $n$ is the number of storeys. The expressions given by Equation 11 are simplified, fit to the results of NLTH analyses. One could expect the actual higher mode drift demands to depend on the ground motion spectral shape and intensity, and the way that the mass, stiffness and strength is provided over the height of the building. However, for the purposes of providing a practical design procedure and recognizing that the first mode will contribute most to the total drift demand, Priestley et al. [5] (and others) advocate for such a simplified estimation of higher mode drifts.

The impact of second-order P-delta effects on a building can also be challenging to assess but it is addressed in a relatively simple manner in Direct DBD. As explained in [5] and [11], Pdelta effects are accounted for in Direct DBD by increasing the required base shear strength by an amount $V P-\Delta$ given by:

$V_{P-\Delta}=C \frac{m_{e} \cdot g \cdot \Delta_{d}}{H_{e}}$

where $g$ is the acceleration due to gravity and $C$ is a factor to account for the impact that hysteretic properties have on P-delta effects, recommended by Priestley et al. [5] to be taken as 0.5 for RC frame structures. Checks are also made to ensure that the P-delta stability coefficient given by Equation 13 does not exceed 0.30 , as this can represent a point of dynamic instability for systems responding in the non-linear range.

$\theta_{P \Delta}=\frac{m_{e} \cdot g \cdot \Delta_{d}}{V_{b} H_{e}}$

where the symbols have been defined previously. Note that the numerator in the above expression represents the second-order overturning demand and the denominator represents the overturning resistance.

Torsion is a third phenomenon that complicates the design and assessment of a building. When designing new structures, Priestley et al. [5] argue that torsion can be effectively mitigated (for the ultimate limit state) by ensuring that the strength eccentricity is zero. However, strength and stiffness eccentricities may be present in existing buildings and hence the likely torsional response should be accounted for as part of a detailed assessment. Beyer et al. [12] and more recently Fox et al. [13] have proposed methods to estimate nominal torsional rotations that are based on effective stiffness concepts and generally perform reasonably well. However, the author is not aware of simplified but accurate means of accounting for torsion.

\section{Formulation of Expressions for the Rapid Assessment of Storey Drift Demands}

As explained in the introduction to this paper, the aim of this work is to provide a rapid means of assessing drift demands on RC frame buildings. To do this, the simplified design expressions reviewed in the previous sections are rearranged to provide the following expressions for peak storey drift demands:

$\theta_{c}=P S V \sqrt{\frac{\varepsilon_{y} A_{r}}{2 C_{y} g H_{n} f_{s S}^{1.5}}}$ for $P S V<\sqrt{\frac{\varepsilon_{y} A_{r} C_{y} g H_{n} f_{S S}^{0.5}}{2}}$

$\theta_{c}=\frac{0.28 P S V^{2}}{C_{y} g f_{s S} H_{n}}+\frac{0.36 \varepsilon_{y} A_{r}}{\sqrt{f_{s S}}}$ for $P S V \geq \sqrt{\frac{\varepsilon_{y} A_{r} C_{y} g H_{n} f_{s s}^{0.5}}{2}}$

where $C_{y}$ is the ratio of the base shear resistance, $V_{b}$, to building weight, and all other symbols have been defined earlier. The equations are specified for different ranges of $P S V$ as Equation $14 \mathrm{a}$ is considered valid in the elastic range whereas Equation $14 \mathrm{~b}$ is applicable for the inelastic range associated with higher values of $P S V$.

Application of Equation 14 requires information on the building height, $H_{n}$, number of storeys, $n$, beam lengths and section depths, expected reinforcement strength, $f_{y}$, and base shear strength as a fraction of the building weight (to give $C_{y}$ ). The engineer then computes the beam aspect ratio, $A_{r}$, (dividing a representative beam length by the beam section depth), the yield strain, $\varepsilon_{y}$, of the reinforcement (as bar strength divided by modulus of elasticity), and the substitute structure factor by inserting the number of storeys into Equation 2. Subsequently, the PSV expected to indicate the transition from elastic to inelastic response is found using the term on the right side of Equation 14 and following this, the drift demands for different values of PSV are computed using Equation 14. The drifts obtained should then be amplified to account for P-delta and higher mode effects but prior to explaining how to do this, the procedure used to arrive at the above equations is explained in the paragraphs below.

Equation 14b has been obtained by substituting Equation 6 into Equation 8, substituting the result and Equations 3 to 5 into Equation 10, and then rearranging terms. The limit on the base shear in Equation 10 has not been included and thus the expression is likely to be inaccurate for short period buildings. However, it is noted that even 2-storey RC frame structures could well have initial periods (based on cracked section properties) beyond the spectral acceleration plateau and hence, 
Equation $14 \mathrm{~b}$ should be applicable to a wide range of RC frame buildings.

Equation 14a has been formulated by first identifying the factors that most affect the period of vibration of a $\mathrm{RC}$ frame building. To this extent, recall that the period of vibration for a SDOF system is given by:

$T=2 \pi \sqrt{\frac{M}{K}}$

For the first mode period of a multi-storey frame, the mass in Equation 15 should be taken as the effective mass (Equation 3) and the stiffness can be found as the base shear strength divided by the yield displacement. The yield displacement can be computed as the product of the RC frame yield drift and effective height (i.e. $\Delta_{y}=0.5 \varepsilon_{y} A_{r} H_{e}$ ) or by rearranging Equation 6 to find the drift required for a system ductility of 1.0, and inserting this drift within Equation 5 (which will give an equivalent result). The definition of yield displacement here is an equivalent SDOF system yield displacement rather than the displacement at which a member (or storey) is first expected to yield (which could instead be obtained by substituting the yield drift directly into Equation 5). Consequently, the period of an $\mathrm{RC}$ frame (with cracked section stiffness properties) can be estimated as:

$T=2 \pi \sqrt{\frac{H_{n} \varepsilon_{y} A_{r} f_{S S}^{1.5}}{2 C_{y} g}}$

This expression for the period of vibration should not be used for design, unless estimating drift demands, as it will give longer periods than typically used for code design methods.

Recognising also that the spectral displacement demand is equivalent to the equivalent SDOF displacement demand on an elastic system, the peak drift demand can be related to spectral displacement and velocity demands as:

$\theta_{c}=\frac{S_{d}}{H_{n} f_{S S}^{1.5}}=\frac{P S V . T}{2 \pi H_{n} f_{S S}^{1.5}}$

where $S_{d}$ is the spectral displacement demand at period, $T$. Substituting Equation 16 into Equation 17, the peak drift demand in the elastic range can be obtained as per Equation 14a.

Earlier, it was shown that in displacement-based design, P-delta effects can be accounted for by increasing the required base shear strength by an amount given by Equation 12 . For assessment, it has been pointed out [14] that this approach is equivalent (in the constant velocity portion of the response spectrum) to amplifying the drift demands by the factor $\alpha_{c}$ :

$\alpha_{c}=\frac{1}{\left(1-C \theta_{P \Delta}\right)}$

where $\theta_{P \Delta}$ is the P-delta stability coefficient (Equation 13) and $C$ is a function of hysteretic type. For RC frames, substituting in the expressions presented earlier, Equation 18 becomes:

$\alpha_{c}=\frac{1}{\left(1-0.5 \frac{\theta_{c} f_{s S}}{c_{y}}\right)}$

Finally, the response of higher modes on peak storey drift demands can also be accounted for by simply dividing the drift obtained from Equation 14 by the higher mode drift factor computed using Equation 11.

In light of the above, to allow for both P-delta and higher mode effects in a simplified fashion, one can first compute the storey drifts according to Equation 14 and then amplify the result to obtain the peak storey drift demand, $\theta_{\max }$, as follows:

$\theta_{\max }=\frac{\alpha_{c} \theta_{c}}{\omega_{\theta}}$ where $\theta_{c}$ is the $1^{\text {st }}$-order drift demand (from Equation 14), $\alpha_{c}$ is the P-delta drift amplification factor (Equation 19) and $\omega_{\theta}$ is the higher mode drift factor (Equation 11).

The approach proposed above is intended for the assessment of median drift demands. Investigations into the dispersion in these demands should be part of future research.

\section{Limitations of the Rapid Assessment Approach}

A number of simplifications and assumptions have been made in formulating Equation 20 and thus the limitations of its use should be identified.

One major simplification to underline is related to the spectral shape. Real ground motions obviously do not impose spectral demands that exactly match code spectra. Furthermore, the approach has been formulated considering response in the constant velocity portion of the response spectrum. At long periods and high intensities, response will tend to enter the constant-displacement region of the response spectrum and this will imply that the drifts do not increase as rapidly with intensity as the simplified method might suggest. On the other hand, whilst uncommon, very stiff short RC frame buildings may have periods of vibration that lie within the constant acceleration portion of a response spectrum and this would also jeopardise the accuracy of the method.

Another key simplification has been to estimate the yield drift of the RC frames using an expression that depends solely on the length and depth of the beams, as well as the yield strain of longitudinal reinforcement. Although Priestley [15] presents experimental evidence to strongly support this relationship, reviewed in the appendix, it is evident that variations in column sizes and storey heights will impact on the accuracy of the expression and, subsequently, on the predicted drift demands.

A characteristic of the expression for displaced shape presented in Equation 1 that could also affect the accuracy of the approach, is the manner with which the lateral resistance is provided over the height of the building. In [5], it is recommended that $10 \%$ of the base shear is lumped at roof level when setting storey shear resistance requirements. This recommendation is also made in the New Zealand loadings standard and it helps to limit drift demands over the upper levels of a building. The displaced shape expression of Priestley et al. [5] (and given by Equation 1) was verified by comparing peak displacement and storey drift profiles from NLTH analyses, but only for frames designed with the recommended strength distribution in mind. Therefore, if significant changes in strength or stiffness are present from one storey to another, it is not expected that the simplified approach would provide accurate estimates of peak drift demands. Nevertheless, it is expected that for most modern RC frame buildings, engineers would have provided a good distribution of strength and ensured that abrupt stiffness changes are avoided.

Another point that should be recognised is that the allowance for P-delta effects implies a linear amplification of demands when in reality, for high P-delta stability coefficients at which collapse due to dynamic instability becomes imminent, the demands are expected to increase exponentially. This issue is avoided in design by limiting the stability coefficient at the design intensity level. However, as the rapid assessment method proposed herein is a function of intensity, it should be recognised that the accuracy is likely to be reduced at high intensities.

No allowance or discussion of soil-foundation-structure interaction has been made to this point. Thus, if foundation deformations are likely to be significant, the accuracy of the approach could be limited. Furthermore, if the RC frames are located on liquefiable sites, the rapid drift estimation procedure would quickly become very inaccurate at high intensity levels. 
Finally, no allowance has also been made for torsion. Significant torsional response is also something that engineers will typically design-out by minimising stiffness and strength eccentricities, or increasing the overall resistance to limit drifts and displacements. Nevertheless, there are a number of questions as to the best means of estimating torsional response and as the rapid methodology proposed here does not make allowance for torsion, it is likely to be inaccurate for buildings with significant in-plan irregularities.

\section{ALTERNATIVE SIMPLIFIED METHODS}

\section{Use of Period-Height Relationships}

While the approach proposed herein is rapid because it only requires application of a number of equations, without timeconsuming structural analysis, an even simpler assessment procedure can be followed if the period of vibration of a building is estimated as a function of its height. Aninthaneni and Dhakal $[16,17]$ have developed versatile equations to estimate the natural period of moment resisting and braced frames by taking into account the stiffness of frame members. Crowley and Pinho [18] provide a thorough review of various proposals in the literature to relate the period of vibration of a RC building to its height. By comparing modelled and predicted periods of vibration for a number of case study buildings, they concluded that the Eurocode 8 [19] period-height relationship for RC frames, given by Equation 21, performed well for bare (as opposed to masonry infilled) RC frames.

$T=0.075 H_{n}^{0.75}$

where $H_{n}$ is the building height in metres.

With knowledge of the period of vibration of a building, and assuming that the equal-displacement rule is applicable, Equation $21 \mathrm{can}$ be used to obtain the $1^{\text {st }}$ mode displacement demand directly from response spectra. Subsequently, Equation 5 can be used to relate the system displacement demand to a peak storey drift demand. This implies that the peak storey drift can be estimated as: $\theta_{\max }=\frac{S_{d}}{\omega_{\theta} f_{S S}^{1.5} H_{n}} \approx \frac{0.075 P S V}{\omega_{\theta} 2 \pi f_{S S}^{1.5} H_{n}^{0.25}}$

where $S_{d}$ is the spectral displacement demand at the period of the building, $\omega \theta$ is the higher mode drift factor (from Equation 11) and the right-side of the equation approximates the spectral displacement demand as $S_{d}=T . P S V / 2 \pi$. Note that no allowance for second-order P-delta effects has been made here as it would require knowledge of the weight and base shear resistance of the building, which is presumably unknown in this simplified formulation.

\section{GAUGING THE PERFORMACNE OF THE RAPID ASSESSMENT PROCEDURE}

In order to gauge the performance of the proposed procedure, the peak storey drift demands obtained from non-linear dynamic analyses of a set of case study modern RC frame buildings will be compared with those predicted by the proposed expressions as well as those obtained using periodheight relationships.

\section{Description of the Case Study Buildings}

Raghunandan et al. [20] developed design solutions and nonlinear models for a large set of RC frame buildings as part of a study into the effects of ground motion duration on collapse risk. The 2-storey, 4-storey and 8-storey RC frame architype buildings designed by Raghunandan et al. [20] for sites in Los Angeles and Seattle are selected for examination in this work. Figure 2 illustrates the buildings, which are relatively regular in height and plan. These buildings have been selected owing to the availability of information related to both the design and assessment of the systems via non-linear time-history analyses. In addition, because the modelling and analysis of the RC frames was not conducted by researchers active in the field of displacement-based design or assessment, the buildings should represent an impartial test of the displacement-based prediction equations proposed in this work.

Buildings examined herein were designed by Raghunadan et al. [20] according to IBC 2012 as special moment resisting frames for two sites: (1) Los Angeles, and (2) Seattle.

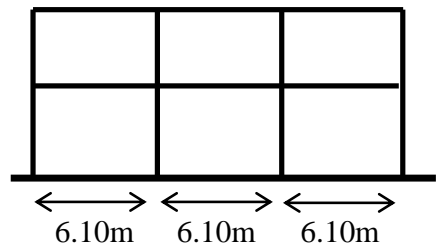

2-storey RC frame

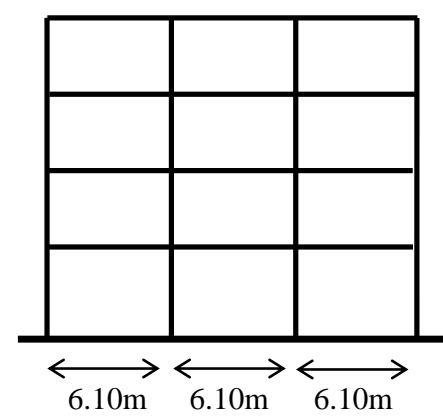

4-storey RC frame

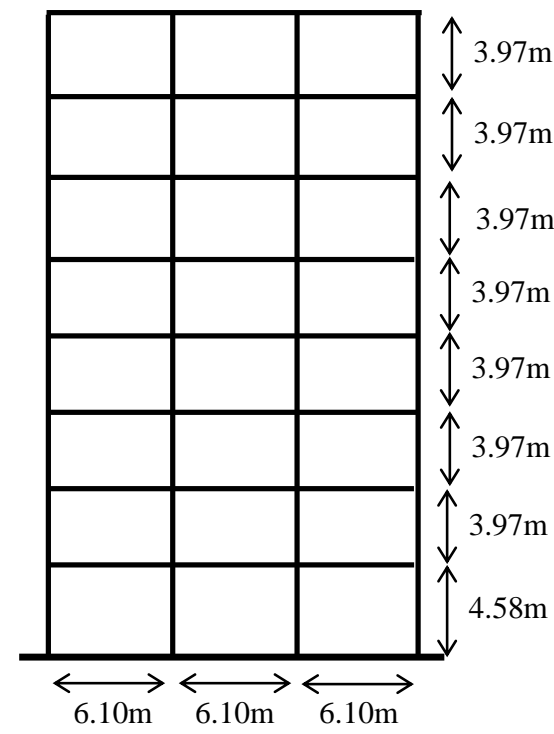

8-storey RC frame

Figure 2: Elevation of the case study buildings (from Raghunandan et al. [20]) used to assess the performance of the simplified approach. 
Table 1: Summary of design information for the case study buildings.

\begin{tabular}{|c|c|c|c|c|c|c|}
\hline \multirow[b]{2}{*}{ Number of storeys, $\mathrm{n}$} & \multicolumn{3}{|c|}{ Los Angeles case-study buildings } & \multicolumn{3}{|c|}{ Seattle case-study buildings } \\
\hline & 2 & 4 & 8 & 2 & 4 & 8 \\
\hline Total height, $\mathrm{H}_{\mathrm{n}}(\mathrm{m})$ & 8.53 & 16.46 & 32.31 & 8.53 & 16.46 & 32.31 \\
\hline Base Shear Coefficient, $\mathrm{C}_{\mathrm{y}}$ & 0.54 & 0.31 & 0.14 & 0.44 & 0.22 & 0.10 \\
\hline Re-bar steel grade, $\mathrm{F}_{\mathrm{y}}(\mathrm{MPa})^{[2]}$ & 462 & 462 & 462 & 462 & 462 & 462 \\
\hline Period of vibration, $\mathrm{T}(\mathrm{s})^{[3]}$ & 0.54 & 0.86 & 1.57 & 0.58 & 1.00 & 1.80 \\
\hline Beam aspect ratio, $\mathrm{A}_{\mathrm{r}}{ }^{[4]}$ & 5.70 & 5.70 & 5.70 & 5.70 & 5.70 & 5.70 \\
\hline $\begin{array}{l}{ }^{[1]} \text { Values taken from [20] by multip } \\
{ }^{[2]} \text { Expected rebar yield strength, as } \\
{ }^{[3]} \text { Periods of vibration obtained fron } \\
{ }^{4]} \text { Beam aspect ratios computed usin } \\
\text { reported in [22]. }\end{array}$ & $\begin{array}{l}\text { design } \\
\text { rted in [2 } \\
\text { en-value } \\
\text { length }\end{array}$ & $\begin{array}{l}\text { ar coeffi } \\
\text { s by Rą } \\
\text { d in Rą }\end{array}$ & $\begin{array}{l}\text { ith frame } \\
\text { dan et al. } \\
\text { dan et al. }\end{array}$ & $\begin{array}{l}\text { rength } \mathrm{f} \\
\text { nsiderin } \\
\text { d maxin }\end{array}$ & $\begin{array}{l}\text { d concr } \\
\text { m sectio }\end{array}$ & $\begin{array}{l}\text { tions. } \\
\text { hs }\end{array}$ \\
\hline
\end{tabular}

The buildings were designed according to IBC2012 [21] and as such, were capacity designed to encourage the formation of a beam-sway mechanism during intense earthquake shaking. A summary of relevant design information is reported in Table 1.

The base shear coefficients included in Table 1 have been taken from [20]. For a rapid assessment, one could estimate the base shear coefficient based on historical design practice, with allowance for the likely system overstrength (noting that overstrength factors reported in [20] ranged from 2 to 4). Alternatively, with information on beam section properties, the overturning resistance of all hinges expected to form in a beamsway mechanism could be summed (together with column base hinge strengths estimates) and then divided by the effective height (Equation 4) to give a more accurate estimate of base shear resistance.

Applying the rapid assessment approaches described in the previous sections, the intermediate results presented in Table 2 are obtained. P-delta amplification factors are not reported as these were computed for each value of intensity examined. Table 2 also includes a comparison of the predicted periods of vibration for both of the simplified methods with the analytical periods reported by Raghunandan et al. [20]. It can be seen that the Eurocode 8 expression (Equation 21) tends to significantly underestimate the analytical periods of vibration whereas the simplified method correlates better, slightly overestimating some of the periods reported by Raghunandan et al. [20]. One might have anticipated Equation 21 would underestimate the cracked periods of vibration reported in [20] because it was previously found by Crowley and Pinho [18] to predict periods associated with gross section properties well. The underestimation of period might be considered conservative for a force-based design approach but, as will be demonstrated shortly, it is non-conservative for the estimation of peak storey drift demands.

In order to complete the prediction of storey drift demands, the only information required in addition to that reported in Table 2 is the peak spectral velocity (or other preferred intensity measure). The next section will briefly describe the NLTH modelling and analysis approach, and the intensity of the ground motions used.

Table 2: Intermediate assessment results obtained for the case study buildings.

Los Angeles case-study buildings Seattle case-study buildings

\begin{tabular}{lcccccc}
\hline Number of storeys, $n$ & 2 & 4 & 8 & 2 & 4 & 8 \\
\hline Yield strain re-bar, $\varepsilon y$ & 0.0023 & 0.0023 & 0.0023 & 0.0023 & 0.0023 & 0.0023 \\
\hline Substitute structure factor, $f_{s s}$ & 0.841 & 0.734 & 0.684 & 0.841 & 0.734 & 0.684 \\
\hline Higher mode drift factor, $\omega_{\theta}$ & 1 & 1 & 0.97 & 1 & 1 & 0.97 \\
\hline Period, $T$, estimated from Equation 16 & 0.56 & 0.93 & 1.82 & 0.62 & 1.11 & 2.16 \\
\hline Period, $T$, from Eigen-Value Analyses ${ }^{[1]}$ & 0.54 & 0.86 & 1.57 & 0.58 & 1.00 & 1.80 \\
\hline Period, $T$, estimated using EC8 (Eq. 19) & 0.37 & 0.61 & 1.02 & 0.37 & 0.61 & 1.02 \\
\hline
\end{tabular}

${ }^{[1]}$ Periods of vibration obtained from eigen-value analyses by Raghunandan et al. [20] considering cracked concrete sections. 


\section{NLTH Analysis Approach}

In order to investigate collapse risk, Haselton and Deierlein [22] and Raghunandan et al. [20] describe the refined non-linear modelling approach used to assess the architype structures. Following this, as part of an investigation into duration effects, Bhanu et al. [23] have recently subject the non-linear models developed in [20] to incremental dynamic analyses [24] using the FEMA P-695 far-field ground motion set as well as a set of spectrally-equivalent long-duration ground motions [25]. In this work, the results obtained by Bhanu et al. [23] using the FEMA P-695 ground motion set are used to gauge the performance of the rapid assessment approach proposed herein. Figure 3 presents the geometric mean acceleration and velocity response spectra for the ground motion set, which consists of 44 ground motions (22 pairs) recorded in earthquake events ranging in magnitude from 6.5 to 7.6. Details of the ground motion set can be found in [26].

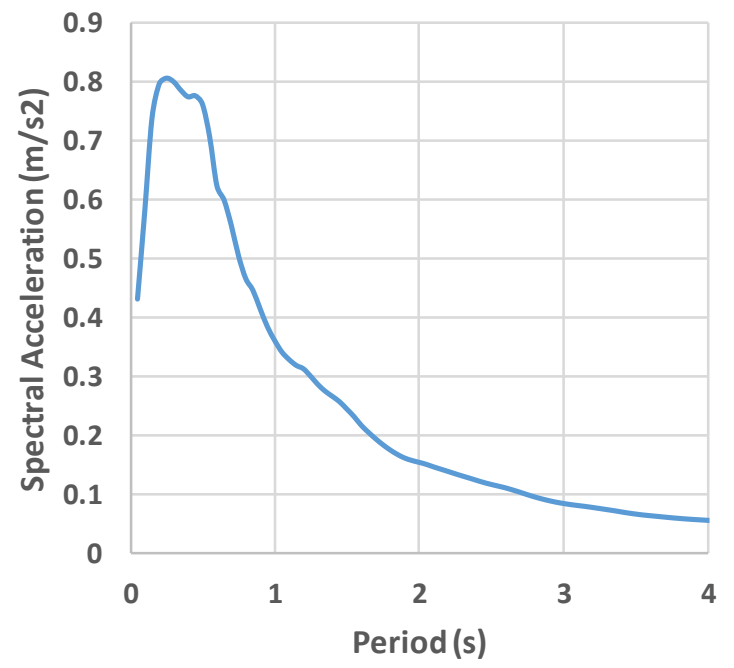

(a)

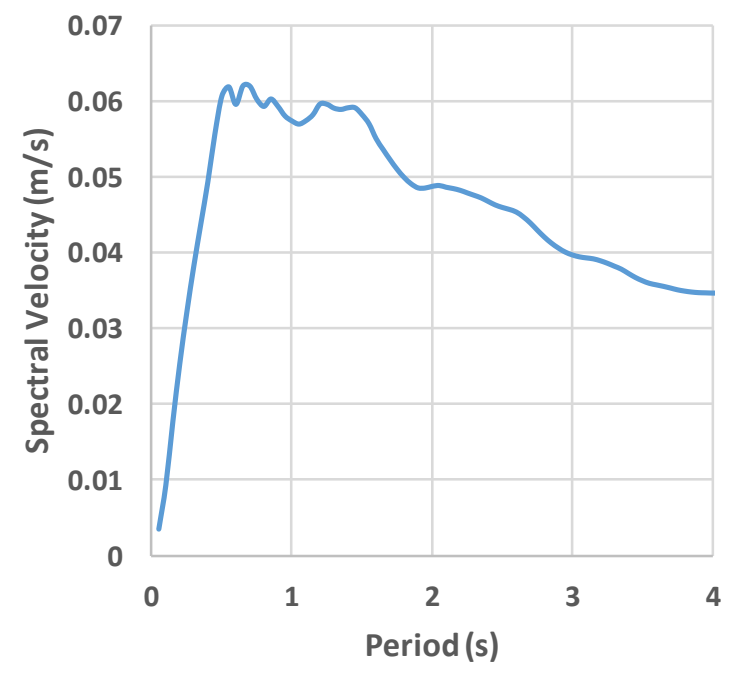

(b)

Figure 3: Geometric mean response spectra of FEMA P-695 far-field ground motion set, as used by Bhanu et al. [23]; (a) acceleration, and (b) velocity response spectrum.

Figure 4 reports the median of the peak storey drifts obtained by Bhanu et al. [23], as a function of peak spectral velocity at the first mode period of the case study buildings. Whilst not shown in the figure, the dispersion in drift demands was low at low intensities (prior to yield) and ranged from around 0.30 to 0.40 at higher intensity levels (not causing collapse). The periods of vibration used for this correspond to those in Table 1 and the spectral velocity refers to the geometric mean spectral velocity of the FEMA P-695 far-field set. Also included in Figure 4 are the peak storey drifts predicted using Equation 20 and a more traditional period-height relationship in Equation 22. In order to apply both expressions, note that the peak spectral velocity has been assumed to correspond to the spectral velocity demand at the first mode period of the building.

Reviewing the results presented in Figure 4, the peak storey drifts estimated via Equation 20 are seen to correlate well with the results of incremental dynamic analyses. This is encouraging, particularly given that considerable time and expertise is required to develop the non-linear models and run the incremental dynamic analyses. Also note from Figure 4 that the use of a traditional period-height relationship (given by Eurocode 8 [19]) has not been successful in predicting peak storey drift demands. As Equation 21 was seen to underestimate the cracked building periods, it is perhaps not a surprise to see that peak storey drift demands are significantly underestimated. Furthermore, because the equal-displacement rule has been assumed, the period-height relationship does not successfully predict the exponential increase in drift demands at higher intensities, rendering the method even more non-conservative for seismic assessment. In contrast, the proposed approach appears to be a little conservative at higher intensities but not excessively.

The proposed method has been tested here using frames designed to US codes and so one could question how well it would perform for RC frames designed according to other codes. As the method depends on the RC frame characteristics that are considered to most affect the yield drift, stiffness and non-linear behaviour, it is expected that performance should be similar for frames designed to other codes, provided that they include capacity design requirements to ensure formation of a beam-sway mechanism, and provided that a reasonable distribution of strength and stiffness has been adopted over the height of the building (i.e. in line with that prescribed by the standards). However, future research could look to confirm this.

\section{CONCLUSIONS}

This paper has proposed a simplified means of quickly estimating storey drift demands on RC frame buildings. Expressions for peak storey drift demand have been proposed as a function of peak spectral velocity, and a number of RC frame characteristics that should be relatively easy to obtain or estimate. The approach has been developed by utilising concepts and simplifications available from displacementbased seismic design and assessment methods, and includes simplified means of allowing for complex phenomena such as P-delta and higher mode effects.

Anticipated limitations in the accuracy and applicability of the rapid assessment procedure have been underlined. The performance of the approach has been gauged by comparing predicted storey drift demands with those obtained from rigorous non-linear time-history analyses for two sets of 2storey, 4-storey and 8-storey RC frame buildings. The excellent correlation between rigorous and simplified drift estimates suggests that the approach proposed will be useful for rapidly assessing the likelihood of damage to a range of drift-sensitive elements in modern RC frame buildings. There are, however, limitations in the accuracy of non-linear time-history analyses and so future research should aim to further verify the method by comparing drift predictions with those recorded in instrumented buildings. 

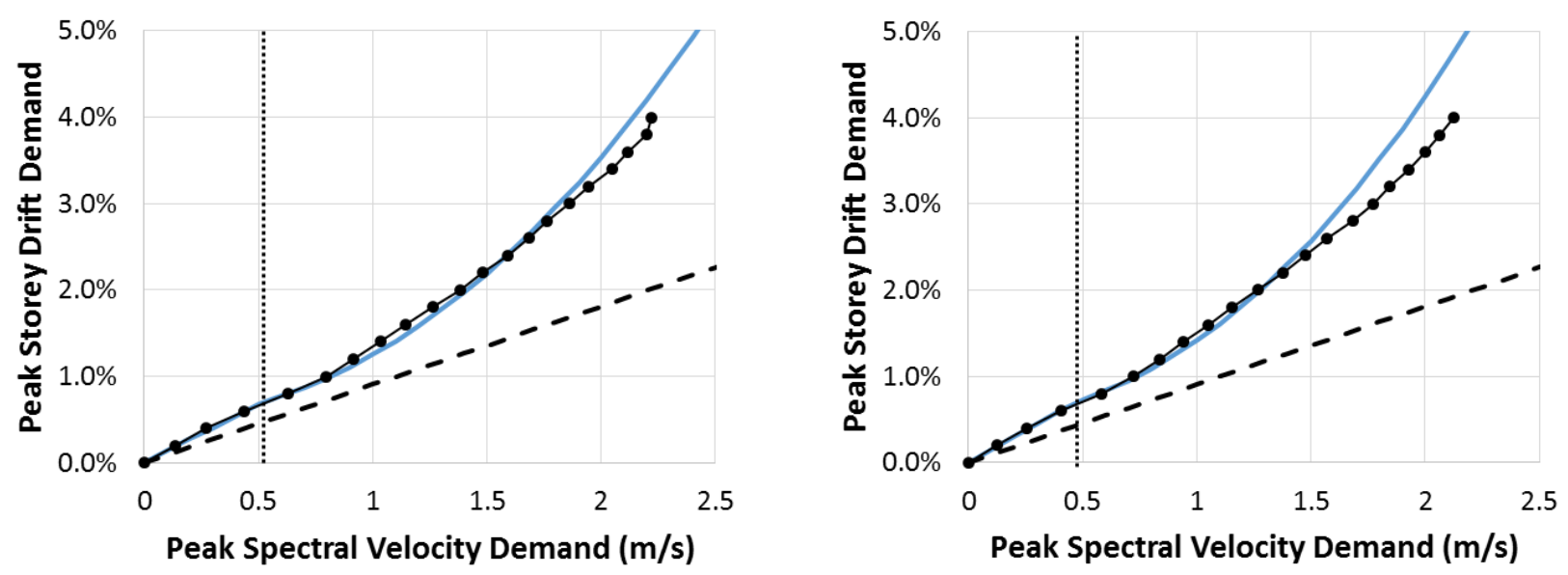

(a)

\section{$\rightarrow$ Results of incremental dynamic analyses \\ Elastic-inelastic transition as per Eq.(14)}

- - - Estimate using EC8 period-height relationship

- Prediction using Eq.(20)
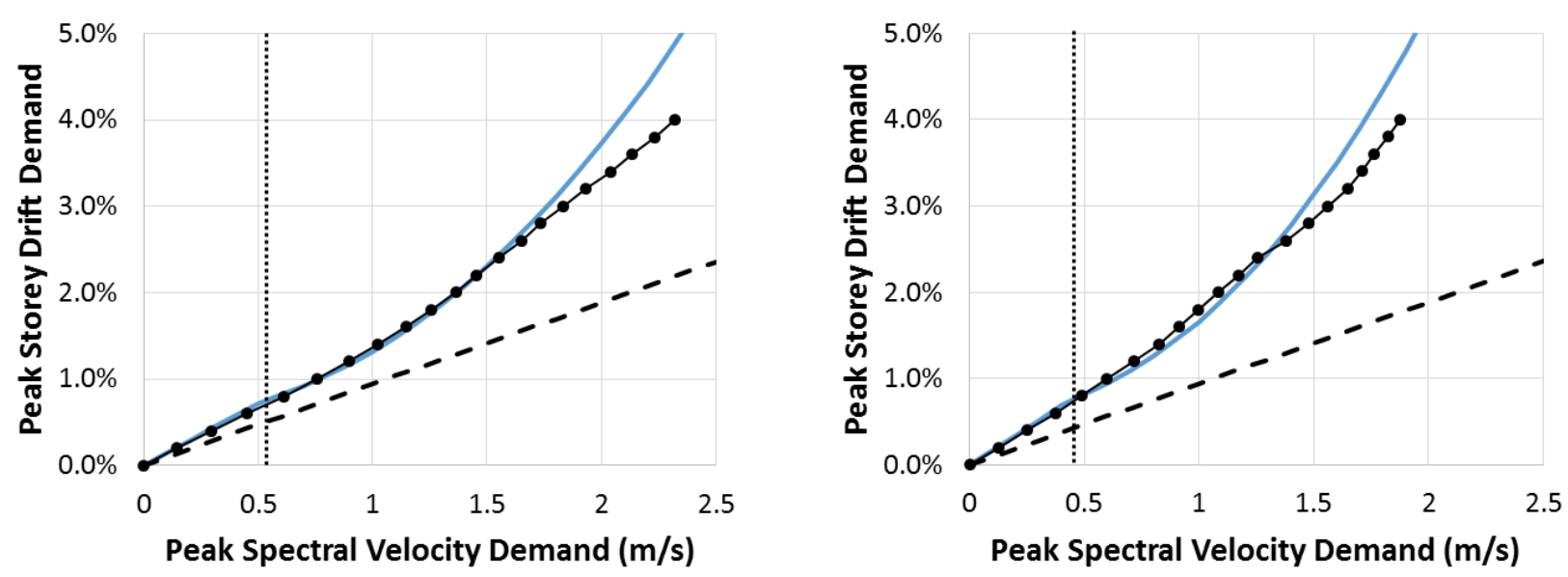

(b)
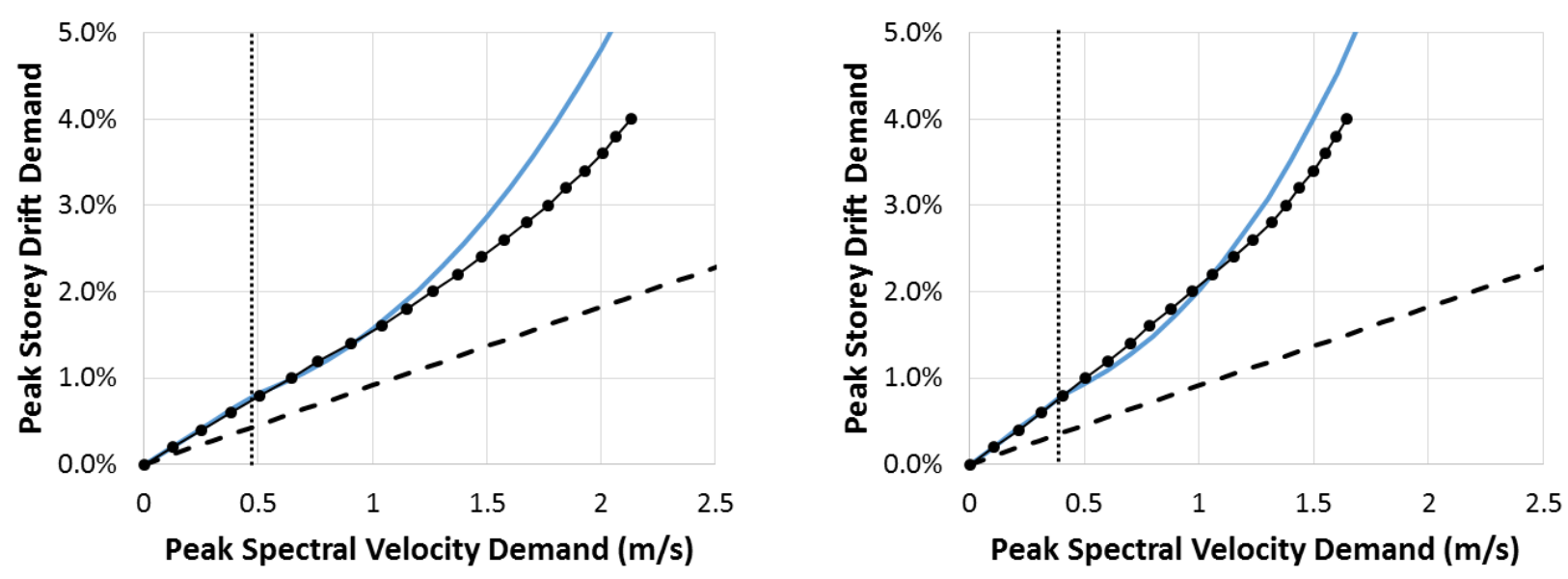

(c)

Figure 4: Median of peak storey drift demands obtained from incremental (non-linear) dynamic analyses from [23] together with peak drift estimates obtained via rapid assessment methods for (a) 2-storey, (b) 4-storey and (c) 8-storey Los Angeles (left) and Seattle (right) architype structures. 


\section{ACKNOWLEDGEMENTS}

The author gratefully acknowledges that the work for this paper has only been possible because of the 2018 EQC/NZSEE Ivan Skinner Award. The author also thanks Ken Elwood for challenging him (in a friendly manner) to develop the assessment approach and Vishvendra Bhanu and Reagan Chandramohan for sharing the analysis results.

\section{REFERENCES}

1. Cubrinovski M, Bradley B, Elwood KJ, Johnston D, Wotherspoon L, Sullivan TJ and Orchiston C (Under Review). "Wellington's Earthquake Resilience: Lessons from the 2016 Kaikōura Earthquake" Earthquake Spectra.

2. Kestrel (2017). "Wellington City Council Targeted Assessment Programme following the Kaikoura Earthquake of 14 November 2016". Technical Report, Kestrel Group Ltd, Wellington, NZ.

3. Matthews J (2004). "Hollow-Core Floor Slab Performance following a Severe Earthquake". Doctoral Dissertation, University of Canterbury, Christchurch, NZ.

4. Fenwick R, Bull D and Gardiner D (2010). "Assessment of Hollow-Core Floors for Seismic Performance". Department of Civil and Natural Resources Engineering, University of Canterbury, Christchurch, NZ.

5. Priestley MJN, Calvi GM and Kowalsky MJ (2007). "Displacement-Based Seismic Design of Structures". IUSS Press, Pavia, Italy.

6. Pettinga JD and Priestley MJN (2005). "Dynamic Behaviour of Reinforced Concrete Frames Designed with Direct Displacement-Based Design". Research Report ROSE - 2005/02, IUSS press, Pavia, Italy.

7. Shibata A and Sozen MA (1976). "Substitute Structure Method for Seismic Design in Reinforced Concrete". Journal of the Structural Division, ASCE, 102: ST1.

8. Gulkan P and Sozen M (1974). "Inelastic response of reinforced concrete structures to earthquake motions". ACI Journal, 71(12): 604-610.

9. Sullivan TJ (2011). "An Energy Factor Method for the Displacement-Based Seismic Design of RC Wall Structures". Journal of Earthquake Engineering, 7(15): 1083-1116.

10. Sullivan TJ (2013). "Highlighting differences between force-based and displacement-based design solutions for RC frame structures". Structural Engineering International, 2/2013.

11. Sullivan TJ, Calvi GM and Priestley MJN (Editors) (2012). "A Model Code for the Displacement-Based Seismic Design of Structures DBD12". IUSS Press, Pavia, Italy, ISBN 97888619807238861980724

12. Beyer K, Dazio A and Priestley MJN (2008). "Seismic Design of Torsionally Eccentric Buildings with $R C U$ Shaped Walls". Research Report ROSE-2008/03, IUSS Press: www.iusspress.it.

13. Fox MJ, Beyer K and Sullivan TJ (2017). "Application of a recently proposed displacement-based assessment procedure for asymmetric-plan RC wall buildings".
Proceedings 16th World Conference on Earthquake Engineering, 9-13 January, Santiago, Chile, Paper 2048.

14. Sullivan TJ, Pennucci D, Piazza A, Manieri S, Welch DP and Calvi GM (2013). "General aspects of the displacement based assessment approach". in Developments in the Field of Displacement-Based Seismic Assessment, Edited by Sullivan TJ and Calvi GM, IUSS Press, Pavia, Italy, ISBN: 978-88-6198-090-7.

15. Priestley MJN (1998). "Brief Comments on Elastic Flexibility of Reinforced Concrete Frames and Significance to Seismic Design". Bulletin of the New Zealand Society for Earthquake Engineering, 31(4): 246-259.

16. Aninthaneni PK and Dhakal RP (2016). "Prediction of fundamental period of regular frame buildings". Bulletin of the New Zealand Society for Earthquake Engineering, 49(2): 175-189.

17. Aninthaneni PK and Dhakal RP (2017). "Prediction of lateral stiffness and fundamental period of concentrically braced frame buildings". Bulletin of Earthquake Engineering, 15: 3053-3082, DOI: 10.1007/s10518-0160081-7.

18. Crowley H and Pinho R (2010). "Revisiting Eurocode 8 formulae for periods of vibration and their employment in linear seismic analysis". Earthquake Engineering and Structural Dynamics, 39: 223-235.

19. CEN EC8 (2004). "Eurocode 8 - Design Provisions for Earthquake Resistant Structures, EN-1998-1:2004: E". Comite Europeen de Normalization, Brussels, Belgium.

20. Raghunandan M, Liel AB and Luco N (2015). "Collapse Risk of Buildings in the Pacific Northwest Region due to Subduction Earthquakes". Earthquake Spectra, 31(4): 2087-2115.

21. International Code Council (2012). "International Building Code". Pasadena, CA, USA.

22. Haselton CB and Deierlein GG (2007). "Assessing seismic collapse capacity of modern reinforced concrete moment frame buildings". Report No. 156, The John A. Blume Earthquake Engineering Center, Stanford, CA, USA.

23. Bhanu V, Chandramohan $R$ and Sullivan TJ (in Production). "Quantifying the impact of ground motion duration on the capacity of reinforced concrete frame structures". Earthquake Engineering and Structural Dynamics.

24. Vamvatsikos D and Cornell CA (2002). "Incremental dynamic analysis". Earthquake Engineering and Structural Dynamics, 31: 491-514.

25. Chandramohan R, Baker JW and Deierlein GG (2016). "Quantifying the influence of ground motion duration on structural collapse capacity using spectrally equivalent records". Earthquake Spectra, 32(2): 927-950. DOI: 10.1193/122813EQS298MR2.

26. FEMA (2009). "Quantification of Building Seismic Performance Factors". Technical Report FEMA P695. Federal Emergency Management Agency, Washington, DC, USA 


\section{APPENDIX}

\section{Basis of Eq.(6) for the Ductility Demand on RC Frames}

Equation 6 proposes that the ductility demand on an $\mathrm{RC}$ frame is proportional to the storey drift demand divided by the longitudinal reinforcement yield strain and the beam aspect ratio. This expression is equivalent to dividing the storey drift by the yield drift (with an adjustment to convert from a MDOF system into an equivalent SDOF system) where the yield drift expression is based on the proposal of Priestley [15], given by:

$\theta_{y}=0.5 \varepsilon_{y} \frac{L_{b}}{h_{b}}=\frac{\varepsilon_{y} A_{r}}{2}$

Where $\theta_{y}$ is the storey drift ratio at yield, $\varepsilon_{y}$ is the longitudinal reinforcement yield strain, and $\mathrm{Ar}$ is the beam aspect ratio (given by the beam length, $L_{b}$, between column centrelines divided by the beam section depth, $h_{b}$ ).

One could query how applicable the yield drift expression is to New Zealand RC frame structures and whether changes in frame geometry or material properties would significantly affect its accuracy? To answer this above, recall that Priestley [15] collected experimental data from 46 beam-column subassemblage tests, of which 33 were conducted in New Zealand and hence are likely to be representative of New Zealand construction. Furthermore, the specimens included the following range of characteristics:

- Column height/beam length ratio $\left(\boldsymbol{H}_{c} / \boldsymbol{L}_{b}\right): 0.4-0.86$

- Concrete compression strength $\left(\boldsymbol{f}^{\prime} \boldsymbol{c}\right): 22.5-88 \mathrm{MPa}$

- Beam reinforcing steel yield strength $\left(f_{y}\right): 276-$ $611 \mathrm{MPa}$

- Maximum beam reinforcement ratio $\left(\boldsymbol{A}_{\boldsymbol{s}} / \boldsymbol{b}_{w} \boldsymbol{d}\right)$ : $0.53 \%-3.9 \%$

- Column axial load ratio $\left(\boldsymbol{N}_{u} / \boldsymbol{f}^{\prime}{ }_{c} \boldsymbol{A}_{\boldsymbol{g}}\right): 0-0.483$

- $\quad$ Beam aspect ratio $\left(\boldsymbol{L}_{b} / \boldsymbol{h}_{\boldsymbol{b}}\right): 4.4-12.6$
Thus, the dataset collected does cover a broad range of RC frame characteristics that would be expected to encompass most $\mathrm{RC}$ frame buildings found in New Zealand.

Comparing the yield drift values obtained experimentally with those obtained via Equation (A1), Priestley [15] generated Figure A1. If the yield drift expression were perfect, all the dots should lie along the line. The results in Figure A1 show that even though the yield drift expression is not perfect, it is very effective at estimating the storey drift at yield and given this, it provides a simple means of rapidly estimating ductility demands in RC frames.

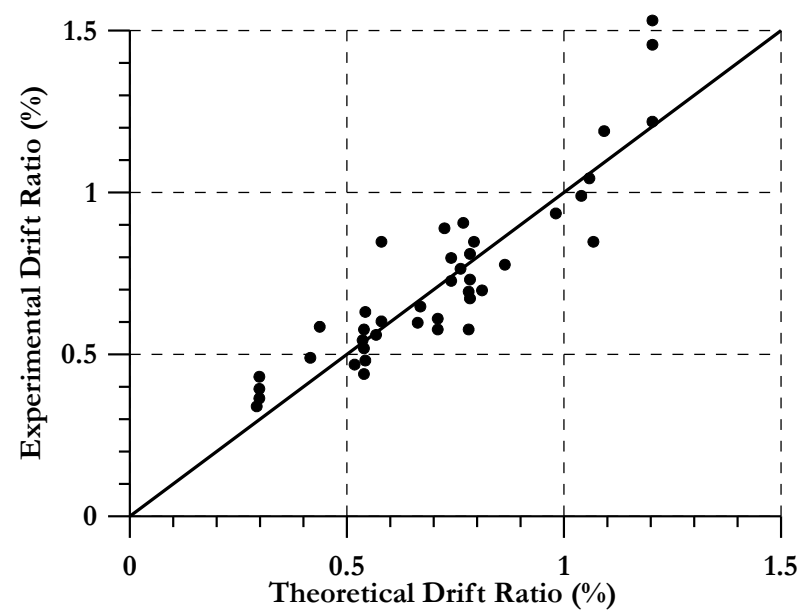

Figure A1: Experimental Yield Drifts of Reinforced Concrete Beam-Column Test Units Compared with Predictions of Equation (A1) from [15]. 